\title{
Modeling Interaction of Fluid and Salt in a Aquifer/Lagoon System
}

\author{
Katsuyuki FUJINAWA¹, Takahiro IBA², Yohichi FUJIHARA ${ }^{3}$, \\ and Tsugihiro WATANABE ${ }^{3}$
}

\begin{abstract}
In order to simulate the dynamic interaction between a saline lagoon and a ground water system, a numerical model for two-dimensional, variable-density, saturated-unsaturated, coupled flow and solute transport (SIFEC) was modified to allow the volume of water and mass of salt in the lagoon to vary with each time step. The modified SIFEC allows the stage of a lagoon to vary in accordance with a functional relation between the stage and water volume of the lagoon, and also allows the salt concentration of the lagoon to vary in accordance with the salt budget of the lagoon including chemical precipitation and dissolution of salt. The updated stage and salt concentration of the lagoon are in turn used as transient boundary conditions for the coupled flow and solute transport model. The utility of the modified model was demonstrated by applying it to the eastern Mediterranean coastal region of Turkey for assessing impacts of climate change on the subsurface environment under scenarios of sea-level rise, increased evaporation, and decreased precipitation.
\end{abstract}

${ }^{1}$ Corresponding author: Department of Civil and Environment Engineering, Shinshu University, Wakasato 4-17-1, Nagano, 380-8553 Japan; +81-26-269-5285; fax +81-26-269-5285; fujinawa@shinshu-u.ac.jp 2Department of Civil and Environment Engineering, Shinshu University, Wakasato 4-17-1, Nagano, 380-8553.

3Research Institute for Humanity and Nature, 457-4 Motoyama, Kamigamo, Kita-ku, Kyoto, 603-8047 Japan. 


\section{Introduction}

Natural ground water systems often play an important role in the hydrologic balance of surface-water bodies such as lakes or lagoons. Vanek (1993) suggested that density-driven convection may play an important role in determining the direction of flow and the distribution of solutes in ground water and coastal pond system. Crowe (1993) applied a dynamic hydrologic model with a series of routing coefficients to assess lake-groundwater systems, and quantified ground water inflow to, and discharge from, the lake and changes to the quality, and volume, of water in the lake.

Crowe's (1993) dynamic hydrologic model is a lumped-parameter model, and it is difficult to find physical meaning for the identified coefficients. Physically-based numerical models, which are distributed-parameter models, are widely used to quantify the interaction between aquifers and the surface-water bodies. Hoaglund et al. (2002) applied a steady-state, finite-difference model to three Great Lakes in the USA but without characterizing the impact of Michigan Basin brines on shallow ground water quality. Although most of the conventional approaches generally handle surface-water bodies as fixed head/fixed concentration boundaries, Lee (2000) applied a two-dimensional, transient finite element method to investigate the effects of nearshore recharge on ground water interaction with a lake by indirectly linking ground water with the lake. Sacks et al. (1992) incorporated lake/aquifer interaction in numerical simulations in a manner that allows simulated lake stages to vary in accordance with independently-determined water budgets computed for each lake and calculated a solute budget after each time step to update the lake concentrations. Merritt and Konikow (2000), building on work by Cheng and Anderson (1993,1994) and Sacks et al. (1992), developed a method to include more realistic situations such as coalescence and separation of lakes and developed a set of computer subroutines called the Lake Package to represent lake/aquifer interaction using MODFLOW in conjunction with the solute-transport model MOC3D (Konikow et al. 1996). However, the effect of water of different density in surface-water bodies on ground water flow and solute transport in ground water is not represented by these conventional numerical models.

Since none of the models developed to date include dynamic interaction between saline surface-water bodies and ground water systems, Fujinawa et al. (2005) developed a numerical code for analyzing two-dimensional, variable-density, saturated-unsaturated, coupled flow and solute transport (Saltwater Intrusion by Finite Elements and Characteristics: SIFEC) with a special function to evaluate the interaction between ground water and a salt-water lagoon. An important feature of SIFEC is that the surface-water bodies can interact dynamically with ground water by an exchange of fluid and mass. That is, 
water level and salinity of the surface-water bodies are redefined after each time step of a transient simulation in accordance with calculated results and in turn are used as up-dated boundary conditions for the coupled ground-water flow and mass-transport equations. It should also be noted that the SIFEC formulation for calculating ground water fluxes into and out of the surface-water bodies by finite elements is quite simple, but is based on a completely different concept from that used in the Lake Package of MODFLOW, and that the formulation for the saturated-unsaturated domain by SIFEC is suitable even for simulating tilted aquifer systems having tilted boundaries.

In order to verify the numerical code, Henry's problem for variable-density ground water flow and solute transport (Henry 1964) was solved by SIFEC, and the results were virtually identical to those of Frind (1982). SIFEC was further tested using Elder's problem (Elder 1967), which is another benchmark problem and is closely related to the density-driven fingering phenomena beneath a saline lagoon. The comparison of results by SIFEC with those of Simpson and Clement (2003) for the Elder problem showed that the concentrations obtained by SIFEC have remarkable similarities in fingering patterns with those of Simpson and Clement (Iba et al. 2008). In order to simulate a problem of an evaporating salt lake, which is characterized by downward convection of salt fingers or plumes due to dense brine overlying less dense fluid, Simmons et al. (1999) used a density-dependent saturated-unsaturated transport model (SUTRA). The convection patterns obtained by SIFEC again matched quite well with those of Simmons et al. (1999).

One of the most important features of SIFEC is its ability to incorporate the dynamic interaction of fluid flow and salt transfer between a lagoon and an aquifer system. Thus, SIFEC was further tested to show it could reproduce the results of sand-box experiments conducted by Fujinawa et al. (2005) for salt water intrusion from a saline lagoon. The comparison between results by SIFEC and those of the sand box experiments showed excellent matching for both steady and transient states. A portion of that study is briefly discussed in this paper.

The objectives of this paper are to generalize the basic concepts presented by Fujinawa et al. (2005) and to demonstrate the applicability of the modified SIFEC. While the exchange of water and salt between surface water and ground water is taken into consideration in the same way as the original SIFEC, the model is further modified to include the interaction of the surface-water bodies with shallow aquifer systems for all fields where the surface-water bodies are influenced not only by ground water flow but also by evaporation, precipitation, runoff, overland flow, and exchange of water and salt with sea. The applicability of the modified SIFEC is further demonstrated by an application to the Lower Seyhan River Basin (LSRB) in the eastern Mediterranean coastal region of Turkey, where the water in a salt-water lagoon is denser than that of the Mediterranean Sea. Furthermore, the impact of climate 
change, which may significantly affect the physical conditions of the lagoon, on the subsurface environment in the LSRB is projected under three scenarios.

\section{Governing Equations}

The governing equation for flow of water with variable-density fluid in saturated-unsaturated porous media, based on Bear (1979), is given by

$$
\nabla \bullet\left\{\frac{\mu_{f} K_{f}}{\mu}\left(\nabla h_{f}+\frac{\rho}{\rho_{f}} \nabla z\right)\right\}-\sum_{i=1}^{n_{q}} Q_{i} \delta_{i}=\rho\left(S_{e} S_{s} \frac{\partial h_{f}}{\partial t}+C_{s} \frac{\partial h_{f}}{\partial t}\right)+\varepsilon S_{e} \frac{\partial \rho}{\partial t}
$$

where $\rho$ and $\rho_{f}$ are the density of water and $\mu$ and $\mu_{f}$ are the dynamic viscosity of freshwater, $S_{e}$ is the fractional effective water saturation, $S_{s}$ is the specific storage, $h_{f}$ is the pressure head in terms of the reference fresh water, $C_{s}\left(=\varepsilon \partial S_{e} / \partial h_{f}\right)$ is the soil water capacity, $\varepsilon$ is the fractional porosity, $K_{f}$ is the hydraulic conductivity in terms of the reference fresh water, $Q_{i}$ is the withdrawal rate of a pumping well $i, \delta_{i}$ is the Dirac delta function for the pumping well, and $z$ is the upward vertical coordinate. In Equation 1, equivalent fresh water head is used to account for density differences.

For unsaturated porous media, van Genuchten (1980) provided functional relations for parameters $S_{e}$ and $K_{f}$ in Equation (1) as follows:

$$
\begin{aligned}
& S_{e}=\frac{\theta-\theta_{r}}{\theta_{s}-\theta_{r}} \\
& S_{e}=\frac{1}{\left(1+\left|\alpha h_{f}\right|^{\beta}\right)^{r}}, \quad\left(\gamma=1-\frac{1}{\beta}\right) \\
& K_{f}=K_{f s} S_{e}^{1 / 2}\left\{1-\left(1-S_{e}^{1 / \gamma}\right)^{\gamma}\right\}^{2}
\end{aligned}
$$

where $\theta, \theta_{s}$ and $\theta_{r}$ are the volumetric water content (VWC), the saturated VWC, and the residual VWC, respectively; $\alpha$ and $\beta$ are the characteristic constants of soil to be evaluated from experiments; $K_{f s}$ is the saturated hydraulic conductivity in terms of the reference fresh water.

The governing equation for solute transport of conservative mass in porous media is given by

$$
\nabla \cdot D \nabla c-\nabla \cdot(\mathbf{v} c)=\frac{\partial c}{\partial t}
$$

where $\mathbf{v}$ is the pore velocity vector; $D$ is the hydrodynamic dispersion coefficient; $c$ is the relative salt concentration defined by using the density of sea water $\rho_{s}$ and freshwater $\rho_{f}$ as

$$
c=\left(\rho-\rho_{f}\right) /\left(\rho_{s}-\rho_{f}\right)
$$

Equations 1 and 5 are coupled via Equation 6 .

The dispersion tensor is defined by 


$$
\begin{aligned}
& D_{i j}=\alpha_{i j k m}\left|v_{k} \| v_{m}\right| /|v|+D_{m} \\
& \alpha_{i j k m}=\alpha_{T} \delta_{i j} \delta_{k m}+\left(\alpha_{L}-\alpha_{T}\right)\left(\delta_{i k} \delta_{j m}+\delta_{i m} \delta_{j k}\right) / 2
\end{aligned}
$$

where $v$ is the average velocity; $v_{k}$ and $v_{m}$ are the velocity components in two coordinate directions, $k$ and $m ; \delta_{i j}$ is the Kronecker Delta; $D_{m}$ is the bulk diffusion coefficient; $\alpha_{L}$ is the longitudinal dispersivity; $\alpha_{T}$ is the transverse dispersivity.

\section{Volume and Mass Balance of the Lagoon}

One of the most important features of this study is that the dynamic interaction of a salt-water lagoon with a ground water system is included in the numerical model. Hence, SIFEC was updated to include an algorithm for calculating the volume and mass balance of the lagoon.

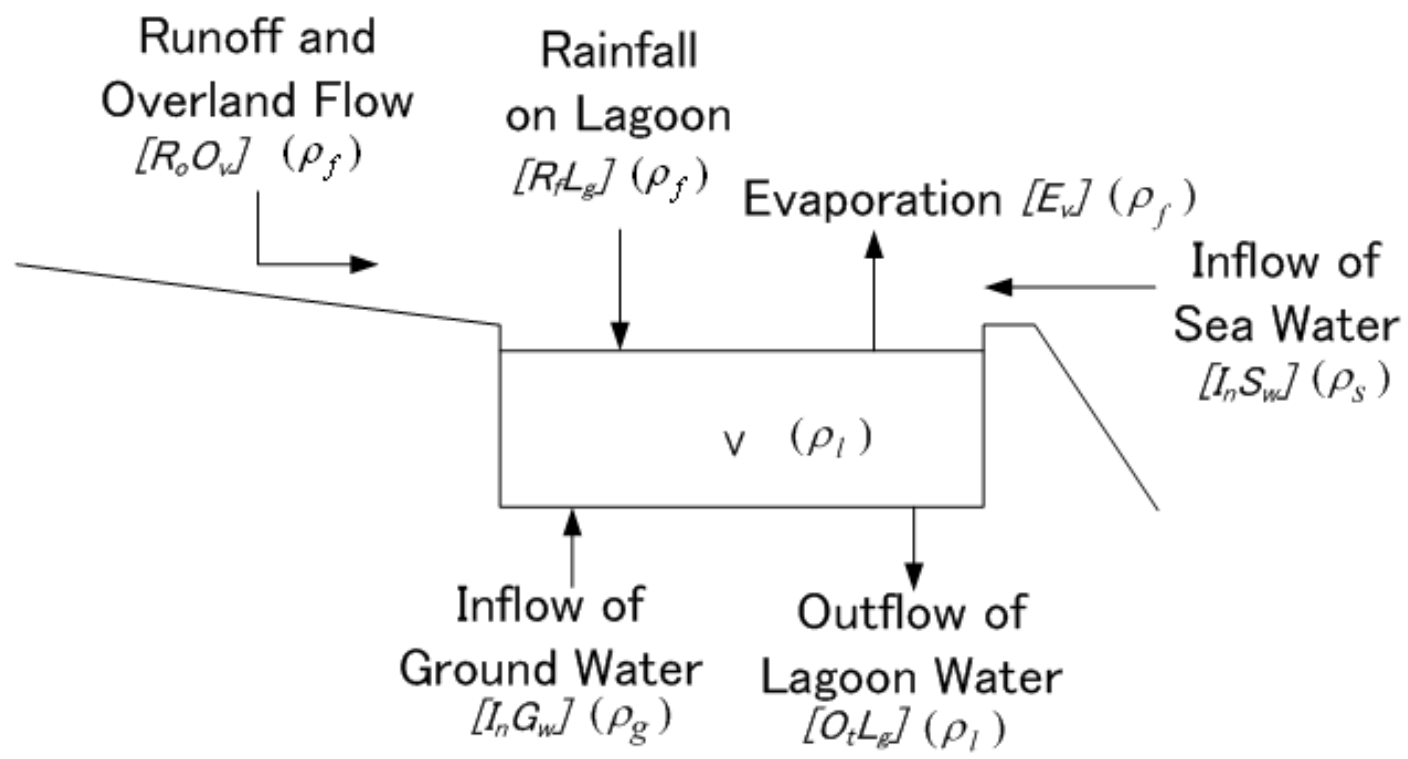

Figure 1. Volume and mass balance of a lagoon connected to the sea.

The salinity of the lagoon can be evaluated by taking the volume and mass balance of the lagoon water into account (Figure 1). By referring to the volume of water contributed by runoff and overland flow, rainfall, and inflow of ground water and sea water together with evaporation and outflow of ground water, the volume of the lagoon water at $t+\Delta t$ is calculated as:

$$
V^{t+\Delta t}=V^{t}+\Delta I_{n} G_{w}-\Delta O_{t} L_{g}+\Delta R_{o} O_{v}+\Delta R_{f} L_{g}-\Delta E_{v}+\Delta I_{n} S_{w}
$$

where $V^{t+\Delta t}$ and $V^{t}$ are the volumes of the lagoon water at $t+\Delta t$ and $t$; $\Delta I_{n} G_{w}$ is the volume recharged by inflowing ground water into the lagoon; $\Delta O_{t} L_{g}$ is the volume of outflow from the lagoon to the subsurface; $\Delta R_{o} O_{v}$ is the combined volume of canal runoff and overland flow; $\Delta R_{f} L_{g}$ is the rainfall into the lagoon; $\Delta E_{v}$ is the evaporation out of the lagoon; $\Delta I_{n} S_{w}$ is the volume of sea water inflow into the lagoon through an inlet; and each $\Delta$ represents an increment during the time span between $t$ and 
$t+\Delta t$. The calculated $V^{t+\Delta t}$ is further converted to the stage of the lagoon at $t+\Delta t$ by using a functional relation between the stage and water volume of the lagoon, which is determined from the bathymetry of the lagoon.

Details of the finite element formulation are provided in appendices 1 and 2. Once Equation A6 in appendix 1 is solved for $\{h\}_{t+\Delta t}$, Equation B8 in appendix 2 is solved for $\{c\}_{t+\Delta t}$, and $\{\rho\}_{t+\Delta t}$ is determined from Equation 6. Then lumped flow rates $Q_{i}$ for node $i$ along the prescribed head boundary of the lagoon, which are the integrated volumes of ground water flux over half of the distance between the two opposite-side boundary nodes next to node $i$, can be evaluated from Equation A6 as:

$$
Q_{i}=\sum_{j=1}^{m}\left\{\left(A_{i j}+E_{i j}^{N} / \Delta t\right) h_{j, t+\Delta t}+B_{i j} \rho_{j, t+\Delta t}-\left(E_{i j}^{N} / \Delta t\right) h_{j, t}\right\}
$$

The summed-up volume of negative $Q_{i}$ is equal to $-\Delta I_{n} G_{w}$, and that of positive $Q_{i}$ is equal to $\Delta O_{t} L_{g}$. Using sets of positive real numbers $\mathbf{R}_{\mathbf{p}}$ and negative real numbers $\mathbf{R}_{\mathrm{n}}$, this relation is written as:

$$
\begin{aligned}
& \Delta I_{n} G_{w}=\sum_{i=1}^{m} \lambda Q_{i}\left\{\begin{array}{l}
\lambda=-1.0\left(Q_{i} \in \mathbf{R}_{\mathbf{n}}\right) \\
\lambda=0.0\left(Q_{i} \in \mathbf{R}_{\mathbf{p}}\right)
\end{array}\right. \\
& \Delta O_{t} L_{g}=\sum_{i=1}^{m} \lambda Q_{i}\left\{\begin{array}{l}
\lambda=0.0\left(Q_{i} \in \mathbf{R}_{\mathbf{n}}\right) \\
\lambda=1.0\left(Q_{i} \in \mathbf{R}_{\mathbf{p}}\right)
\end{array}\right.
\end{aligned}
$$

The incremental volumes other than $\Delta I_{n} G_{w}$ and $\Delta O_{t} L_{g}$ can be based on the projected results of a Regional Climate Model, which are described later. The density of ground water flowing into the lagoon $\rho_{g}$ is calculated using Equation 6 and the solution to Equation B8, while $\rho_{f}$ and $\rho_{s}$ are held constant. The density of the lagoon water $\rho_{l}$ is calculated from the mass balance of the lagoon water as described below.

In order to evaluate the mass balance, it is assumed here that the water never becomes oversaturated with salt, and that precipitated salt dissolves instantaneously when the lagoon water becomes undersaturated. Then, the temporary mass $\dot{M}^{t+\Delta t}$ of the lagoon water at $t+\Delta t$ can be calculated by:

$$
\begin{aligned}
\dot{M}^{t+\Delta t}=V^{t} \bullet & \rho_{l}{ }^{t}+\Delta I_{n} G_{w} \bullet \rho_{g}{ }^{t+\Delta t / 2}-\Delta O_{t} L_{w} \bullet \rho_{l}{ }^{t+\Delta t / 2}+ \\
& \left(\Delta R_{o} O_{v}+\Delta R_{f} L_{g}-\Delta E_{v}\right) \bullet \rho_{f}+\Delta I_{n} S_{w} \bullet \rho_{s}
\end{aligned}
$$

Now, let $\rho_{\max }$ be the maximum density of water saturated by salt, corresponding to the solubility limit.

For $M^{t}=0$ and $\rho_{l}^{t+\Delta t}<\rho_{\max }, \rho_{l}^{t+\Delta t}$ and $M^{t+\Delta t}$, the amount of the salt precipitated in the lagoon at $t+\Delta t$, are simply calculated by:

$$
\rho_{l}^{t+\Delta t}=\dot{M}^{t+\Delta t} / V^{t+\Delta t} \quad, \quad M^{t+\Delta t}=0
$$

For $M^{t}=0$ and $\rho_{l}^{t+\Delta t}=\rho_{\max }$, the incremental amount of precipitated salt $\Delta M$ is evaluated first by:

$$
\Delta M=\dot{M}^{t+\Delta t}-V^{t+\Delta t} \bullet \rho_{\max }
$$


Then, $\rho_{l}^{t+\Delta t}$ and $M^{t+\Delta t}$ result in:

$$
\rho_{l}^{t+\Delta t} \equiv \rho_{\max }, \quad M^{t+\Delta t}=\Delta M
$$

For $M^{t}>0$ and $\rho_{l}{ }^{t+\Delta t}<\rho_{\max }$, all the precipitated salt dissolves into the lagoon water, leading to:

$$
\rho_{l}^{t+\Delta t}=\left(\dot{M}^{t+\Delta t}+M^{t}\right) / V^{t+\Delta t}, \quad M^{t+\Delta t}=0
$$

For $M^{t}>0$ and $\rho_{l}{ }^{t+\Delta t}=\rho_{\max }$, a temporary density of the lagoon water $\dot{\rho}_{l}{ }^{t+\Delta t}$ at $t+\Delta t$ is evaluated first as:

$$
\dot{\rho}_{l}{ }^{t+\Delta t}=\dot{M}^{t+\Delta t} / V^{t+\Delta t}
$$

When $\dot{\rho}_{l}^{t+\Delta t}$ exceeds $\rho_{\max }$, which is constant and equal to around 1200 $\mathrm{kg} / \mathrm{m}^{3}$, extra precipitation of salt takes place. When $\dot{\rho}_{l}^{t+\Delta t}$ is less than $\rho_{\text {max }}$, dissolution of precipitated salt takes place. Then, $\Delta M$ can be calculated from:

$$
\Delta M=V^{t+\Delta t}\left(\dot{\rho}_{l}^{t+\Delta t}-\rho_{\max }\right)
$$

Finally, $\rho_{l}$ and $M$ at $t+\Delta t$ are written as:

$$
\rho_{l}^{t+\Delta t} \equiv \rho_{\max }, \quad M^{t+\Delta t}=M^{t}+\Delta M
$$

\section{Verifying the linkage of ground water to lagoon in SIFEC}

In order to verify the SIFEC code, which interactively links ground water in a shallow aquifer with a saline surface water body, Fujinawa et al. (2005) conducted a series of sand box experiments, and compared numerical results obtained by SIFEC with those of the laboratory experiments. The experiments used a sand box of $700 \mathrm{~mm}$ in width, 400 $\mathrm{mm}$ high on the left-hand side and $300 \mathrm{~mm}$ high on the right-hand side. An impermeable barrier was installed on the right-hand boundary at a height from 250 to $400 \mathrm{~mm}$ to allow store water to represent a lagoon on an inclined surface of the sand box. The water level in a fresh-water chamber along the left boundary was always kept at a height of $380 \mathrm{~mm}$ above the bottom.

The experiments discussed here consisted of three stages. During the first stage, fresh water with density of $0.999 \mathrm{~g} / \mathrm{cm}^{3}$ in the chamber along the right boundary was gradually displaced by salt water with density of $1.03 \mathrm{~g} / \mathrm{cm}^{3}$ by keeping the water level at a height of $300 \mathrm{~mm}$ above the bottom while the lagoon stores the whole discharged water allowing the stage of the lagoon to change with time. When a steady state was reached, the first-stage experiment was terminated. At the beginning of the second stage, the salt-water level at the right boundary was shifted instantaneously up to the height of $356 \mathrm{~mm}$, which was maintained during the second stage. When an equilibrium was reached, the second-stage experiment was terminated. At the beginning of the third stage, the water level of the lagoon was shifted instantaneously down to $336 \mathrm{~mm}$, and was maintained there during the third stage. When equilibrium was reached, the third-stage experiment was terminated.

Figure 2 shows the computed concentrations of $0.1,0.5$, and 0.9 
(solid lines) and the experimental concentration of 0.5 (closed circles) together with velocity vectors at equilibrium states for the first (1-e), second (2-e), and third (3-e) stages together with an intermediate state at 244 seconds $(3-244 \mathrm{~s})$ from the start of the third-stage experiment. During the first stage, salt water did not intrude the sand domain (Figure 1-e). However, the rise in the saltwater level on the right boundary from 300 $\mathrm{mm}$ to $356 \mathrm{~mm}$ caused saltwater to intrude into the sand domain and raised the stage of the lagoon (Figure 2-e) until a new equilibrium was reached. The instantaneous drop of the stage of the lagoon from that of the equilibrium state $(2-e)$ induced a significant intrusion of salt water into the sand domain and caused a drastic discharge of saline water into the lagoon (Figure 3-e). Furthermore, transition zones at the equilibrium states are narrower than those in the transient state (Figure 2), and near the toe at the bottom where horizontal component of the velocity vectors is zero, the transition zones become relatively narrow owing to the absence of dispersion. Figure 2 also shows that the critical zone, where outflow of fresh ground water along the lagoon floor changes into saline ground water, was represented quite accurately by the numerical model.

The volume of the lagoon was numerically evaluated using Equation 9. In order to verify the water balance of the model, the equilibrium levels of the lagoon were measured for the first and second stage and compared with the calculated ones. For the first stage, the calculated level was 318 $\mathrm{mm}$ while the observed was $317 \mathrm{~mm}$. For the second stage, the calculated level was $367 \mathrm{~mm}$ while the observed was $362 \mathrm{~mm}$. The calculated and observed levels of the lagoon are also shown in Figure 2 by solid lines and open circles respectively, and are in excellent agreement. Figure 3(a) shows the temporal change in the depth of the lagoon along the right boundary for the second stage. The stage of the lagoon rose rapidly at the beginning and then gradually reached an equilibrium level.

With regard to verification of the ground water portion of the code, an excellent matching between the calculated and observed concentration was obtained for both equilibrium and transient states (Figure 2). Since the salt concentration in the lagoon water was not measured, the direct verification of the code for the lagoon water concentration was not possible. However, it should be noted that the temporally-evaluated stage and salt concentration of the lagoon were in turn reflected as the 

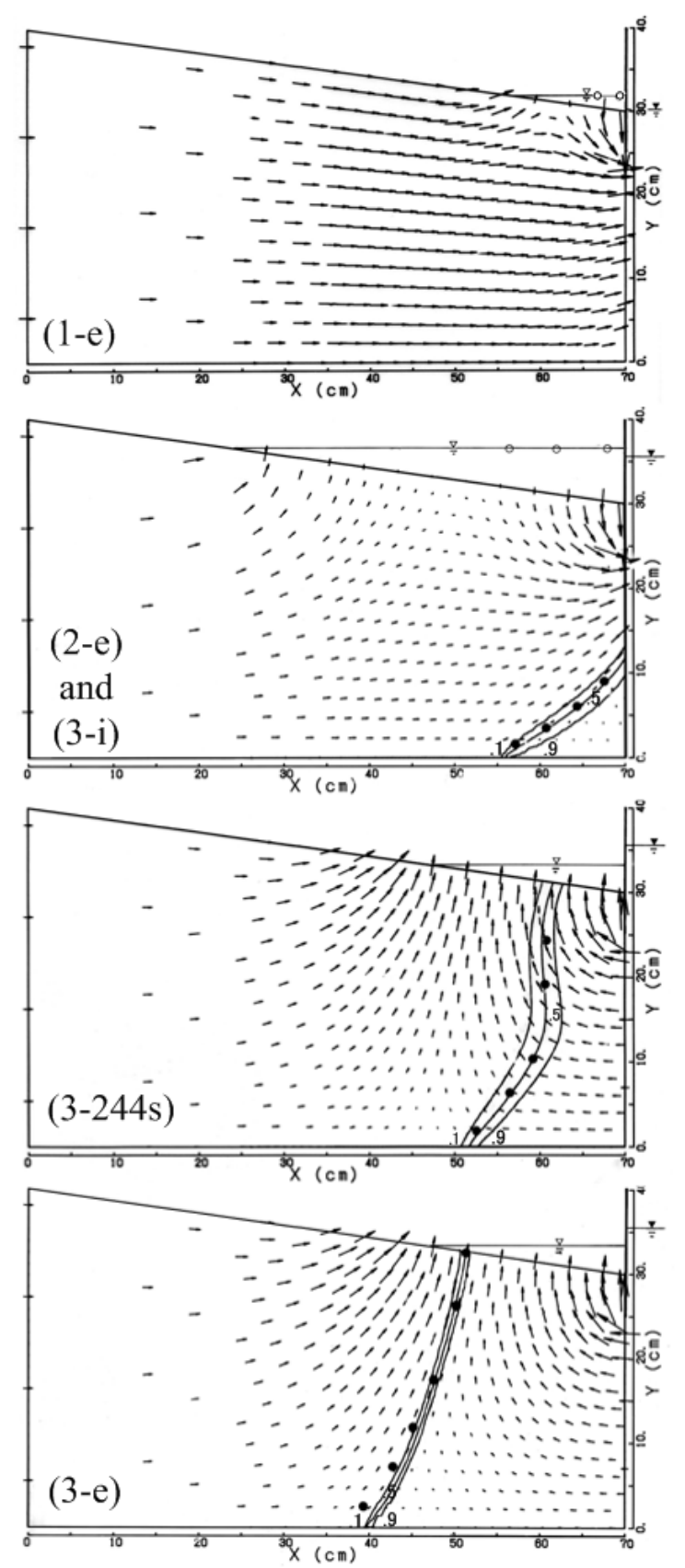

Figure 2. Comparison of concentrations obtained by SIFEC (solid lines) with those of sand box experiment (closed circles): (1-e) equilibrium state of the 1 st stage, (2-e and $3-i)$ equilibrium state of the 2 nd stage and initial state of the 3rd stage, (3-244s) after $244 \mathrm{sec}$ of the $3 \mathrm{rd}$ stage, (3-e) equilibrium state of the $3 \mathrm{rd}$ stage, and comparison of pooled-water levels by experiments and simulations (open circles at equilibrium state for (1-e) and (2-e)): (reproduced from Fujinawa et al. 2005). 

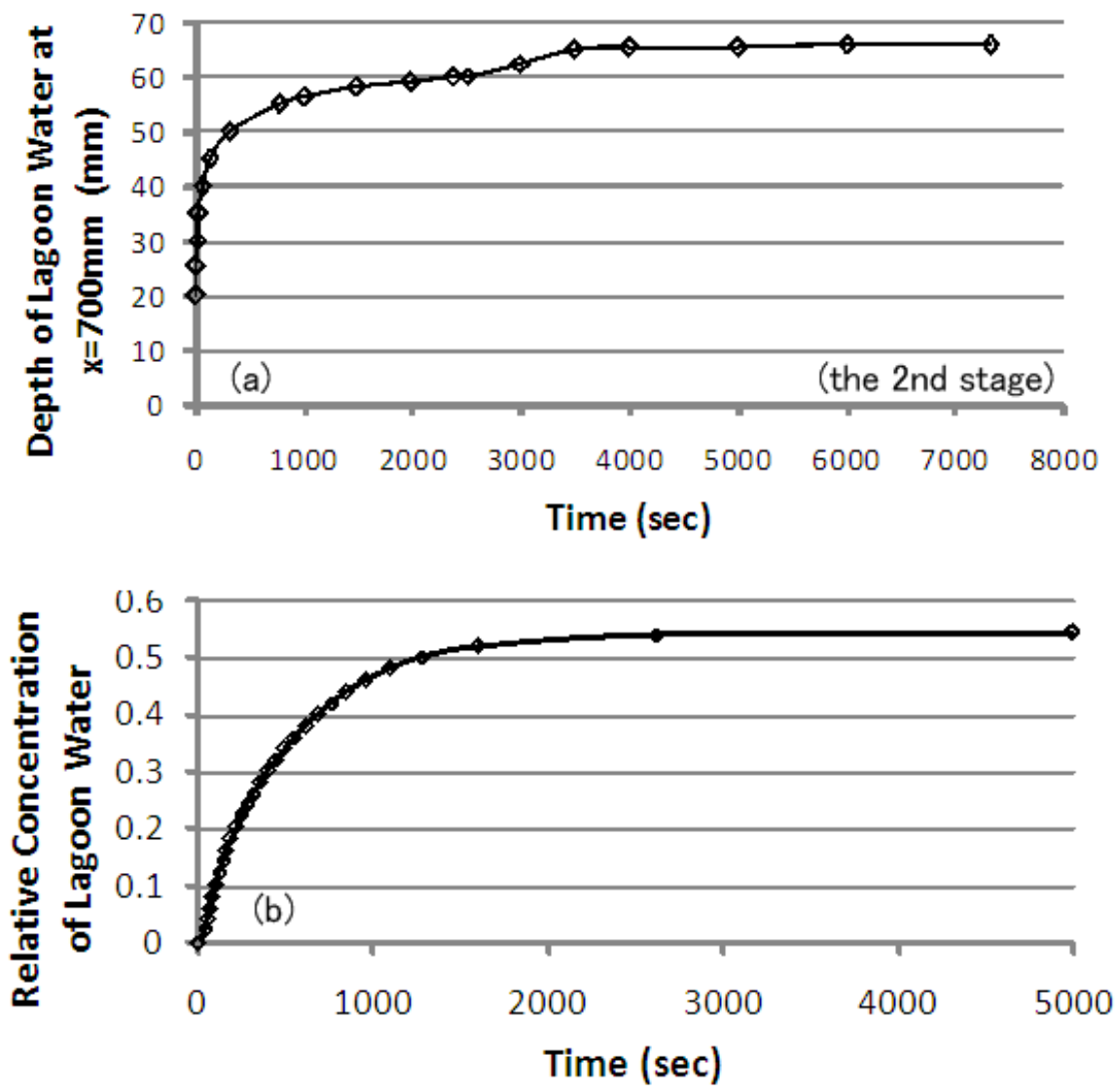

Figure 3. Simulated changes in (a) the depth of lagoon water at $x=700$ $\mathrm{mm}$ during the 2nd stage and (b) the salt concentration of lagoon water relative to salt water in the right chamber during the 3rd stage.

transient boundary conditions for the coupled flow and mass-transport equations. This means that if the transient stage and concentration of the lagoon had not been simulated accurately, the numerical results for the ground water portion would not have been accurate. Figure 3(b) shows the simulated temporal change in the relative concentration of the lagoon water for the third stage. The curve of the concentration was smoother than that of the stage shown in Figure 3(a), and the concentration at the elapsed time of $244 \mathrm{sec}$ was 0.22 . A more detailed description of this work is given in Fujinawa et al. (2005).

\section{Application of the modified SIFEC to the Lower Seyhan River Basin \\ Hydrogeology and Physiography of the LSRB}

The LSRB is bounded to the south by the Mediterranean Sea and to the north by the Adana Basin, which is one of the largest accumulations of Miocene sediments in southern Anatolia (Gurbuz 1999). The Quaternary sediments of the LSRB consist of thick deposits of silty clay 
which are underlain by the Kuransa formation, which is composed of sand, gravel, and conglomerates of the Pleistocene Epoch, and forms the main aquifer of the LSRB. During the Pleistocene, terrace gravels 50 to $100 \mathrm{~m}$ thick were deposited along the riverbed and the Karici formation, composed of calcareous sediment, was formed by evaporation of ground water. Both the terrace gravels and the Karici formation are restricted in the southern part of the Adana basin.

There are three lagoons in the LSRB. The largest is the Akyatan, which lies parallel to the coastal line. The average width of the lagoon is around $4.5 \mathrm{~km}$, and the bottom of the lagoon is relatively flat. The Akyatan is separated from the adjacent Mediterranean by a beach dune and is artificially kept open through a narrow inlet in the southeast. Thus, the lagoon has an access to the Mediterranean, while fresh surface water discharges into the lagoon through canals (Nazik et al. 1999). The depth of the lagoon varies from 80 to $100 \mathrm{~cm}$ depending on the season. The sand dune in the south of the Akyatan forms a slight ridge in the otherwise flat coastal plain.

The LSRB is characterized by semi-arid weather with dry summers and rainy winters and the annual precipitation in this area varies between 600-800 $\mathrm{mm}$. Irrigation is practiced during summer when water requirements for agriculture are high.

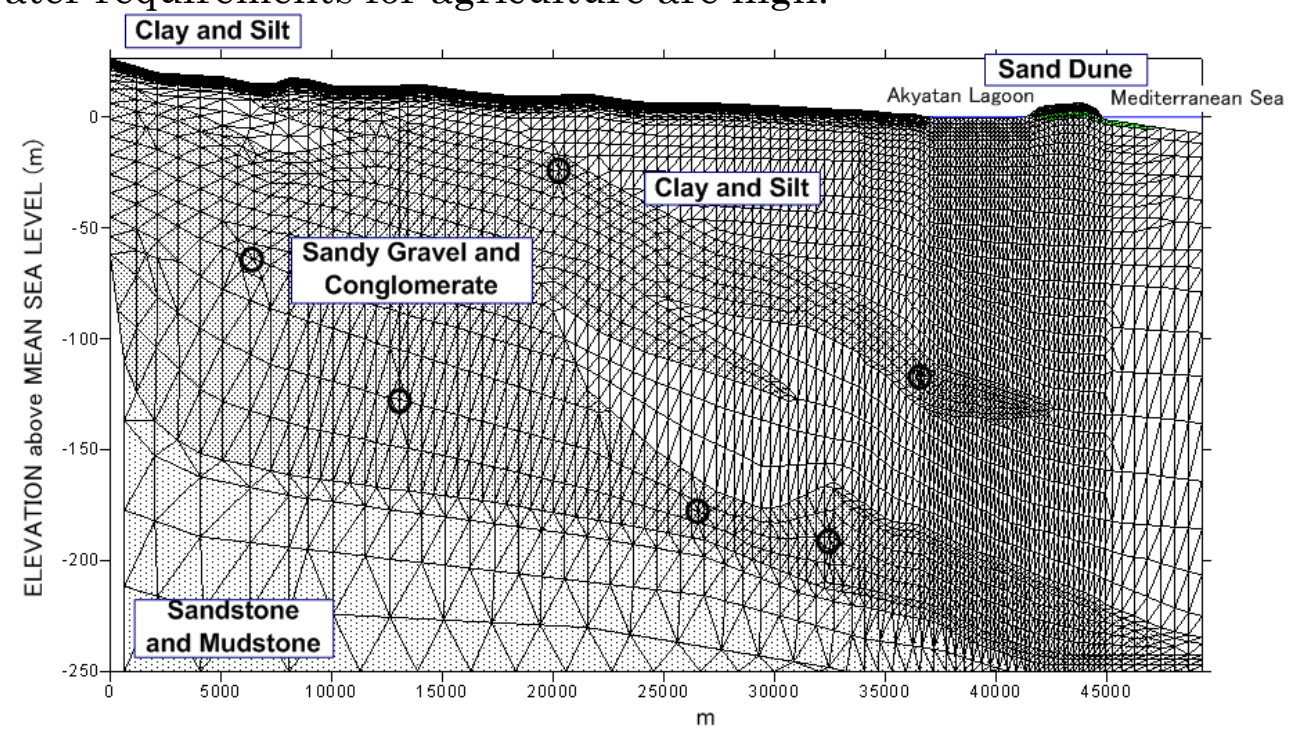

Figure 4. Geologic profile along a flow path and the finite element mesh.

Ground water flow is north to south, almost perpendicular to the coastal line (Kurttas and Karahanoglu 1994). The transect that includes the Akyatan lagoon and the sand dune was chosen as a representative location of the model cross section. Figure 4 shows the simplified geology of the LSRB along the transect together with triangular elements that form the finite element mesh. The geology was determined using the well logs. In the northern part of the LSRB, the Kuransa formation is unconfined. In most of the rest of area, the aquifer becomes confined by an clayey deposit in the alluvium. The Akyatan lagoon is floored with 
silty clays or clayey silts, and the aquifer underneath the lagoon is overlain by a thick low-permeable layer. The base of the aquifer consists of calcareous mudstone and sandstone.

The model domain extends to a depth of $250 \mathrm{~m}$ below mean sea level and its width, including a distance of $5 \mathrm{~km}$ offshore into the Mediterranean, is approximately $50 \mathrm{~km}$. The thickness of the profile is assumed to be $1 \mathrm{~m}$. Fine elements were used near land surface and beneath the lagoon where changes in water saturation, salt concentration, and direction of ground water flow are expected to be significant. Coarser elements were used in the other parts of the domain to minimize the total number of nodes.

\section{Mathematical Model of the LSRB}

Prescribed pressure heads $h_{i}$ assigned to boundary nodes $i$ at $z=z_{i}$ were $H_{f}-z_{i}$ along the inland fresh-water boundary of the aquifer, $\left(H_{s}-z_{i}\right) \rho_{s} / \rho_{f}$ along the inclined sea floor, and $\left(H_{l}-z_{i}\right) \rho_{l} / \rho_{f}$ along the lagoon floor, where $H_{f}, H_{s}$, and $H_{l}$ are the elevations of the water table at the inland boundary, the sea water surface, and the lagoon water surface from a reference level, respectively. The level of the lagoon is set equal to that of the Mediterranean and varies through time in accordance with the sea-level rise adopted in climate projection scenarios. The functional relation between the stage and water volume of the lagoon was evaluated in advance of the projections so that the varying stage could be converted to the relevant water volume of the lagoon in order to evaluate the volume of sea water inflow into the lagoon.

Net recharge was assigned to nodes on the land surface including the sand dune at a rate that varied depending on the climate change scenarios, except for nodes where calculated pressure head is positive and thus the boundary condition is replaced by $h_{f}=0$. No flow was assigned to the rest of the boundaries.

For mass transport, several types of boundary conditions were applied. Constant concentration, $c=0$, was assigned along the left boundary of the aquifer, where fresh ground water flows into the domain. For nodes along the inclined sea floor, constant concentration, $c=1.0$, was assigned if the boundary flux calculated from Equation 9 for the relevant node was positive; otherwise, a no-dispersion boundary was assigned. For nodes along the lagoon floor, time-variable prescribed concentration, $c=\left(\rho_{l}-\rho_{f}\right) /\left(\rho_{s}-\rho_{f}\right)$, was assigned if the flux for the relevant node was positive; otherwise, a no-dispersion boundary was assigned. The nodes along the land surface including the sand dune were assigned as a prescribed concentration boundary, except for the region where outward ground water flux is positive where the boundary is set as a no-dispersion boundary.

Cetin and Diker (2003) investigated the salinity (Total Dissolved Solids) 
of ground water in the LSRB and found that the electric conductivity (EC) of shallow ground water in $50.0 \%$ of the area was between 0.0 and $0.1 \mathrm{~S} / \mathrm{m}$, while EC was between 0.1 and $0.2 \mathrm{~S} / \mathrm{m}$ in $45.5 \%$ of the area and more than $0.2 \mathrm{~S} / \mathrm{m}$ in the remaining $4.5 \%$. Irrigation water has slightly lower EC than shallow ground water. The EC of recharge water was specified as $0.02 \mathrm{~S} / \mathrm{m}$ for the non-irrigated area lying within $8 \mathrm{~km}$ from the sea shore; for the irrigated area lying beyond $8 \mathrm{~km}$ from the Mediterranean, the EC was specified to change linearly depending on the distance from the landward boundary from $0.03 \mathrm{~S} / \mathrm{m}$ to $0.14 \mathrm{~S} / \mathrm{m}$. EC values were input to SIFEC to specify concentration of recharge. The EC values were converted to density by SIFEC and density was converted to the salt concentration relative to the Mediterranean Sea using Equation 6. A no-dispersion boundary was assigned along no-flow boundaries.

\section{Climate Change Projection Scenarios}

According to the $4^{\text {th }}$ Assessment Report (AR4) of the Intergovernmental Panel on Climate Change (IPCC) (Solomon et al. 2007), the projected temperature change during 2090-2099 relative to 1990-1999 lies in the range of $1.1{ }^{\circ} \mathrm{C}$ for the $\mathrm{B} 1$ scenario to $6.4{ }^{\circ} \mathrm{C}$ for the A1FI scenario, while the sea-level rise is projected to be $18 \mathrm{~cm}$ for the B1 scenario to $59 \mathrm{~cm}$ for the A1FI scenario. In order to project impacts of climate change on the ground water system in the LSRB, three scenarios, considering sea-level, evaporation, and precipitation, are constructed following results from the AR4 and those from Kimura et al. (2007) who reported the results of regional climate models for Turkey.

Among the factors affecting the ground water system in the LSRB are sea level, climate, recharge, abstraction, and inland boundary conditions. However, only sea level and climate were considered in the simulations reported here. According to the AR4, the maximum sea-level rise by 2100 projected under A2 of the Special Report on the Emission Scenario is $0.51 \mathrm{~m}$. Thus, a sea-level rise of $5.1 \mathrm{~mm} /$ year was adopted for our projection.

Typical grid spacing in Coupled atmospheric-oceanic General Circulation Models (CGCMs) is 100 to $300 \mathrm{~km}$. Hence, its horizontal resolution is not sufficient to estimate regional climate. Kimura et al. (2007) developed a downscaling technique to construct a Regional Climate Model (RCM) with a grid interval of $8.3 \mathrm{~km}$ by using a Pseudo Global Warming Method and estimated the change in the regional climate of the Seyhan River Basin (SRB) under the A2 scenario in conjunction with the result of two independent CGCMs, developed by the Meteorological Research Institute (MRI) and Center for Climate System Research at the University of Tokyo and the National Institute for Environmental Studies (CCSR/NIES). Kimura et al.'s (2007) values for future precipitation and temperature in the LSRB projected by the MRI-RCM and the CCSR/NIES-RCM were used in our simulation. Evaporation rates were evaluated with the aid of the Penman method. 
The observed current evaporation and precipitation rates are 1471.1 $\mathrm{mm} /$ year and $660.9 \mathrm{~mm} /$ year, respectively, while the average values of the future evaporation and precipitation rates projected for 2070 were $1549.3 \mathrm{~mm} /$ year and $375.2 \mathrm{~mm} /$ year, respectively (Table 1). Since the current maximum depth of the lagoon is less than 1 meter, the salinity of the lagoon water likely will be significantly affected.

Three values of evaporation rate in 2070 were used in scenarios: $1471.4 \mathrm{~mm} / \mathrm{yr}$ (current rate), $1549.3 \mathrm{~mm} / \mathrm{yr}$ (projected rate), and 1510.4 $\mathrm{mm} / \mathrm{yr}$ (average of current and projected rates). Likewise, three values were used for the precipitation rate in 2070: $660.9 \mathrm{~mm} / \mathrm{y}, 375.2 \mathrm{~mm} / \mathrm{y}$, and $518.1 \mathrm{~mm} / \mathrm{y}$. The climatic conditions should be applied both on the land surface and the lagoon. In this study, however, the rates of evaporation and precipitation were directly applied only to the lagoon but not to the land surface.

\begin{tabular}{|c|c|c|}
\hline \multicolumn{3}{|c|}{$\begin{array}{l}\text { Table } 1 \\
\text { The Observed and Projected Values of Precipitation and } \\
\text { Evaporation }\end{array}$} \\
\hline & $\begin{array}{l}\text { Precipitation } \\
(\mathrm{mm} / \mathrm{y})\end{array}$ & $\begin{array}{c}\text { Evaporation } \\
(\mathrm{mm} / \mathrm{y})\end{array}$ \\
\hline Current: (a) & 660.9 & 1471.4 \\
\hline $\begin{array}{l}\text { In 2070, The average of MRI-RCM } \\
\text { and CCSR/NIES-RCM projections: (b) }\end{array}$ & 375.2 & 1549.3 \\
\hline In 2070: $\{(\mathrm{a})+(\mathrm{b})\} / 2$ & 518.1 & 1510.4 \\
\hline
\end{tabular}

Hereafter, scenarios are entitled $\mathrm{S}$ for a sea-level rise of $5.1 \mathrm{~mm} / \mathrm{year}$, and $0, f$, and $h$ for simulations of the effects of precipitation and evaporation under current conditions, projected conditions, and the average of current and projected conditions, respectively. Since each value should vary temporally during each projection run, the values were linearly interpolated from the current values based on year 2000 to the values of the target year of 2070 .

\section{Model Calibration}

According to field measurements, the EC of the Akyatan Lagoon is 6.8 S/m, which is much higher than $5.8 \mathrm{~S} / \mathrm{m}$ in the Mediterranean. In order to convert the values of EC into the relative salt concentration, the EC meter used in the field was calibrated at laboratory in terms of salt water density and temperature. The soil-water characteristics of various 
soils sampled from the LSRB were investigated in the laboratory, and the average van Genuchten's parameters in Equation 3 were identified to be $\alpha=0.414 / \mathrm{m}, \quad \beta=1.23, \theta_{s}=0.531$, and $\theta_{r}=0.197$. Values of hydrogeologic parameters were estimated from a literature survey (Table 2).

The boundary values of water level and water density for the current time period are listed in Table 3 along with those for the projection runs. The net annual recharge rate from precipitation was estimated to be $8.11 \mathrm{~mm}$, while that from irrigation was assumed to be the same as the net annual recharge rate. To represent ground water withdrawal, six representative point sinks were specified within the domain, implying an infinite extent of the sinks perpendicular to the modeled cross section (Figure 4).

\begin{tabular}{|c|c|c|c|c|}
\hline \multicolumn{5}{|c|}{ Hydrogeologic Parameters for the Seyhan River Basin } \\
\hline & $\begin{array}{l}\text { Sandy gravel } \\
\text { and } \\
\text { conglomerate }\end{array}$ & $\begin{array}{l}\text { Sand } \\
\text { dune }\end{array}$ & $\begin{array}{c}\text { Clay } \\
\text { and silt }\end{array}$ & $\begin{array}{c}\text { Sandstone } \\
\text { and } \\
\text { mudstone }\end{array}$ \\
\hline Hydraulic Conductivity (m/day) & 8.6 & 3.45 & 0.1 & 0.04 \\
\hline Specific Storage $(1 / m)$ & $1.3 \times 10^{-5}$ & $4.6 \times 10^{-5}$ & $8.5 \times 10^{-5}$ & $1.0 \times 10^{-6}$ \\
\hline Effective Porosity & 0.22 & 0.22 & 0.22 & 0.22 \\
\hline Longitudinal Dispersivity (m) & 30 & 10 & 7.5 & 3 \\
\hline Transverse Dispersivity (m) & 3 & 1 & 0.75 & 0.3 \\
\hline
\end{tabular}

There are currently more than one thousand wells for agricultural, municipal, and industrial use in the LSRB and the distribution of these wells is relatively uniform. This situation allows us to install representative sinks of infinite extent in the direction perpendicular to the modeled cross section. Considering the location and depth of these wells, we installed six representative point sinks in the two-dimensional model as represented by open circles in Figure 4. During calibration, ground water withdrawal rates at the point sinks were adjusted so that the calculated height of the water table matched those measured at 13 observation wells for the current time period. It should be noted that the adjusted withdrawal rates include the net recharge from the rivers and canals in the LSRB. 


\begin{tabular}{|cccc|}
\hline \multicolumn{4}{|c|}{ Table 3 } \\
& Boundary Conditions & \\
& Mountain Side & Lagoon & Sea Side \\
& (Ground water) & (Lagoon Water) & (Sea Water) \\
\hline Water Level above & 19.0 & 0.0 (Current) & 0.0 (Current) \\
Sea Level (m) & & 0.51 (in 2100) & 0.51 (in 2100) \\
Density of Water at & 1.002 & 1.035 (Current) & 1.030 \\
$20^{\circ} \mathrm{C}\left(\mathrm{g} / \mathrm{cm}^{3}\right)$ & & variable (2070) & \\
\hline
\end{tabular}

The simulated water table coincides quite well with the measured water table for the current time period (Figure 5). Figure 6 shows the calculated distribution of dimensionless concentration defined by Equation 6, representing ground-water salinity (as measured by EC) for the current time period along with ground water velocity vectors. Low salinity of shallow ground water in the inland area is attributed to recharge from irrigation water containing salt up to $0.14 \mathrm{~S} / \mathrm{m}$. A small saline plume, which is drawn downward by convection of ground water due to dense brine in the lagoon, is observed beneath the central part of the lagoon. Initial conditions for the projection scenarios for both pressure head and concentration were specified using the results for the current time period. It was assumed that the net recharge rate is held constant during the projection period.

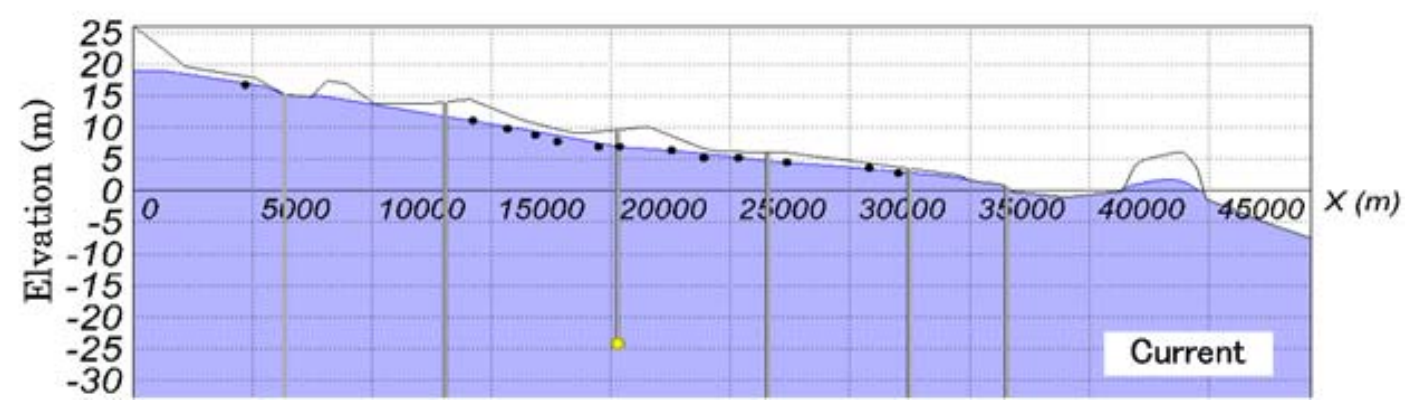

Figure 5. Calibrated (solid line) and observed (closed circles) locations of the water table for the current time period. The horizontal axis is distance from the landward boundary. The heavy vertical lines indicate the location of the representative point sinks (see Figure 4). 


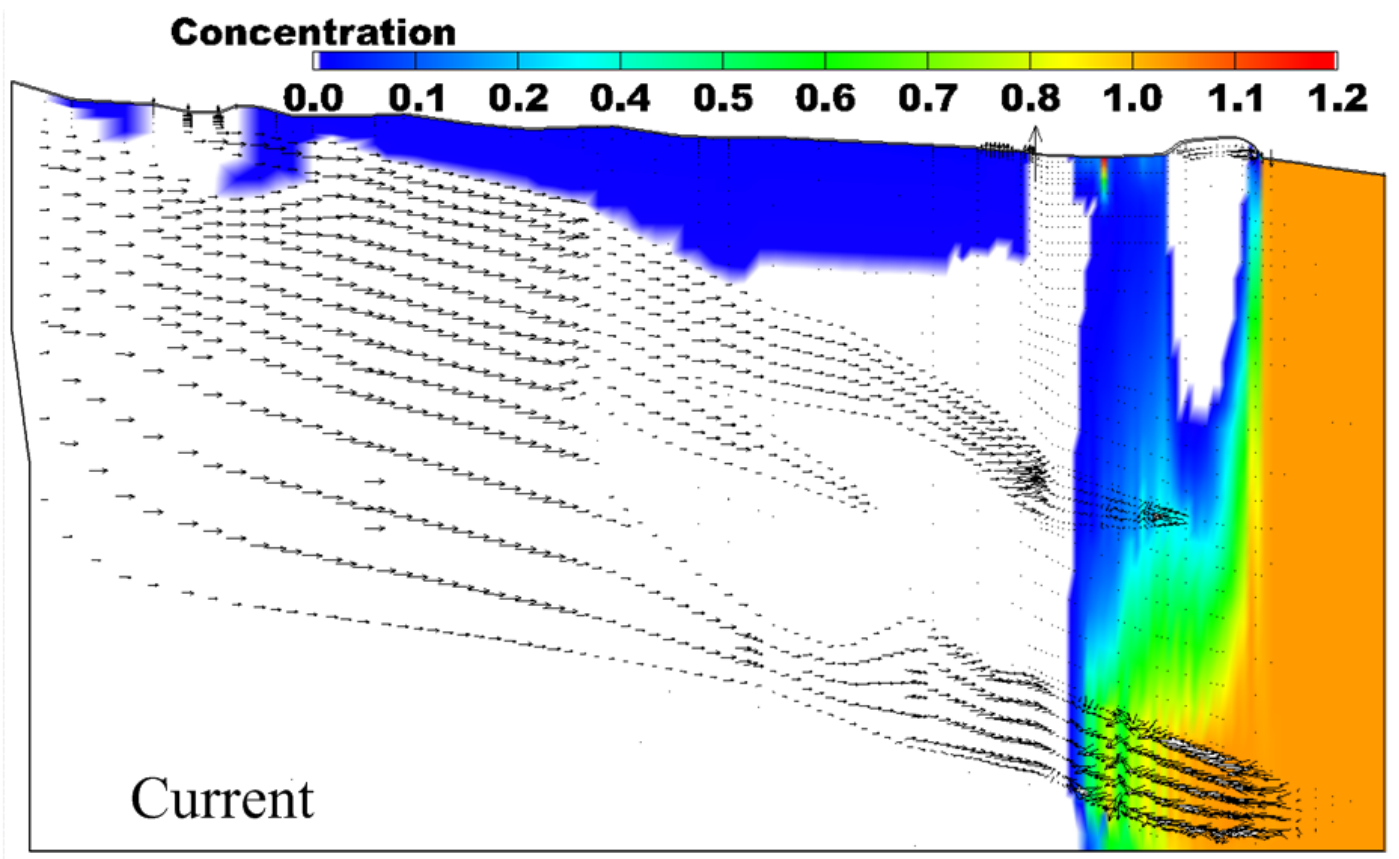

Figure 6. Ground water velocity vectors and salt concentration relative to the Mediterranean Sea for the current time period.

\section{Projected Ground Water Flow}

Locations of the water table projected under the Sh and Sf scenarios indicate that sea-level rise and climate change will not have much effect on the water table. Figure 7 shows ground water velocity vectors near the lagoon for the current time period and those in 2070 projected for the S0, $\mathrm{Sh}$, and Sf scenarios. The vectors for the current time period show that there is a slight downward movement of ground water beneath the central part of the lagoon, which creates the small plume beneath the lagoon as shown in Figure 6. Simmons et al. (1999) also found that evaporation from a salt lake results in dense brine overlying less dense ground water, which is hydrodynamically unstable and leads to downward convection of salt fingers or plumes. The projected velocity vectors beneath the lagoon for scenarios S0, Sh, and Sf show how the convection is enhanced due to increased evaporation and decreased precipitation, and exhibit exactly the same trend as the results of Simmons et al. (1999). It is clear from Figure 7 that the denser the water in the lagoon, the greater the ground water velocities and the more complicated the flow patterns. 


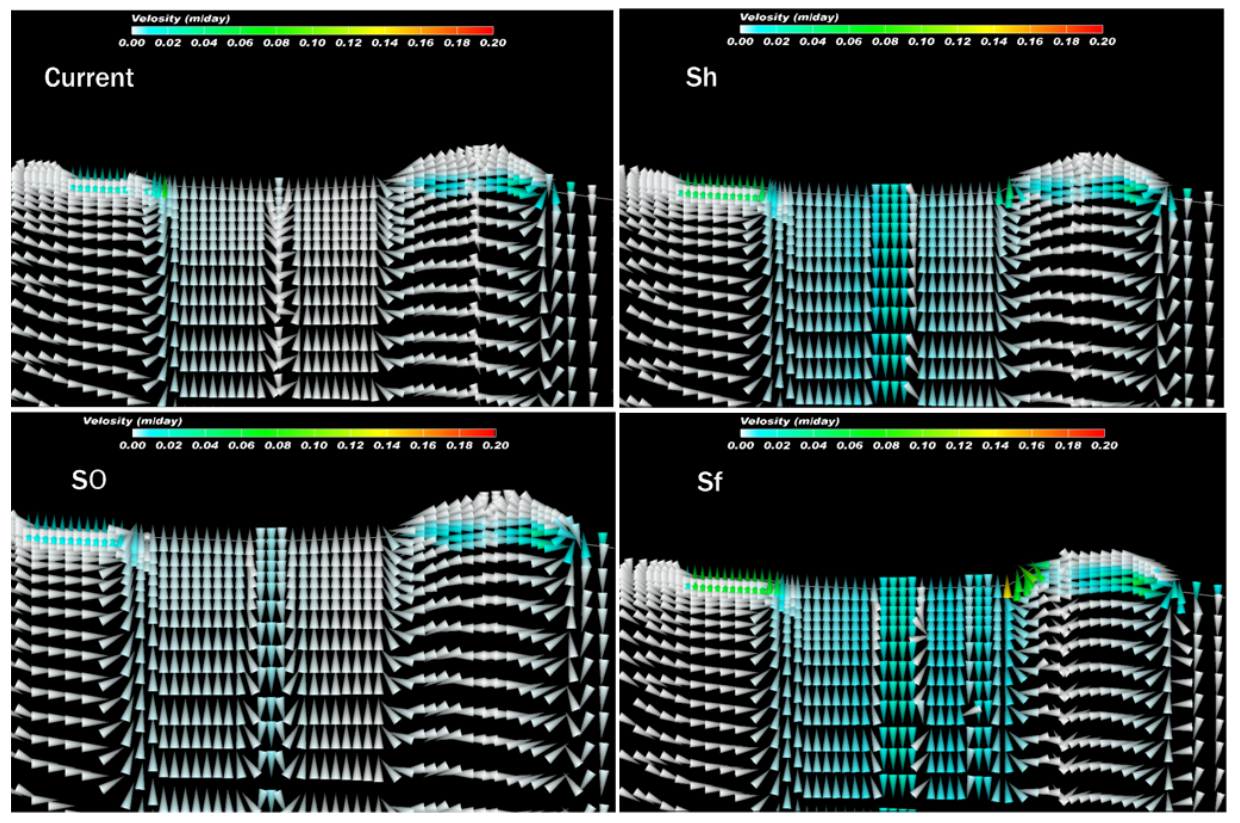

Figure 7. Velocity vectors of ground water near the Akyatan lagoon.

\section{Projected Salinity of Lagoon Water}

There are eight variables in the mass balance equation (Equation 8); namely, $V^{t+\Delta t}, V^{t}, \Delta I_{n} G_{w}, \Delta O_{t} L_{g}, \Delta R_{o} O_{v}, \Delta R_{f} L_{g}, \Delta E_{v}, \Delta I_{n} S_{w}$. Since the stage of the lagoon is held to the level of the Mediterranean, the volumes $V^{t+\Delta t}$ and $V^{t}$ can be evaluated in accordance with the sea level. $\Delta I_{n} G_{w}$ and $\Delta O_{t} L_{g}$ are calculated in the course of the simulation from Equations 9 and 10. $\Delta R_{f} L_{g}$ and $\Delta E_{v}$ are assumed from the climate change scenarios. Hence, the volume of sea water inflow to the lagoon, $\Delta I_{n} S_{w}$, can be calculated from Equation 8 provided that the total volume of runoff and overland flow, $\Delta R_{o} O_{v}$, is known. Since runoff and overland flow are closely related to precipitation, it was assumed here that a simple relation of $\Delta R_{o} O_{v}=\lambda \Delta R_{f} L_{g}$ holds, where $\lambda$ is a constant, and that the salinity of the lagoon water does not change during the 70-year period from current conditions. It should be noted that the second assumption may cause slight underestimation of the projected effect of the lagoon on the ground water salinity.

It is possible to identify $\lambda$ by means of the projection run for the period from 2000 to 2070 under the scenario of zero sea-level rise and no climate change so that the density of the lagoon water $\rho_{l}$ in Equations 11 and 12 remains unchanged with time. Then $\lambda$ equals 1.14 , for which value the change in the lagoon water salinity was negligibly small compared to results from the S0 scenario (Figure 8).

Once $\lambda$ is fixed, projections under the various scenarios can be performed. In Figure 8, temporal changes in the calculated salt concentration of the lagoon water under the S0, Sh, and Sf scenarios are 
shown. Without change in evaporation and precipitation, the salinity of the lagoon water eventually decreases below that of the sea water as shown by the curve S0 due to the rising sea level. On the other hand, the increased evaporation and decreased precipitation as projected under scenarios Sf and Sh raise the salt concentration in the lagoon water drastically. Although the newly proposed model can handle precipitation/dissolution processes in the lagoon, none of the simulated cases for the LSRB included precipitation or dissolution of salt.

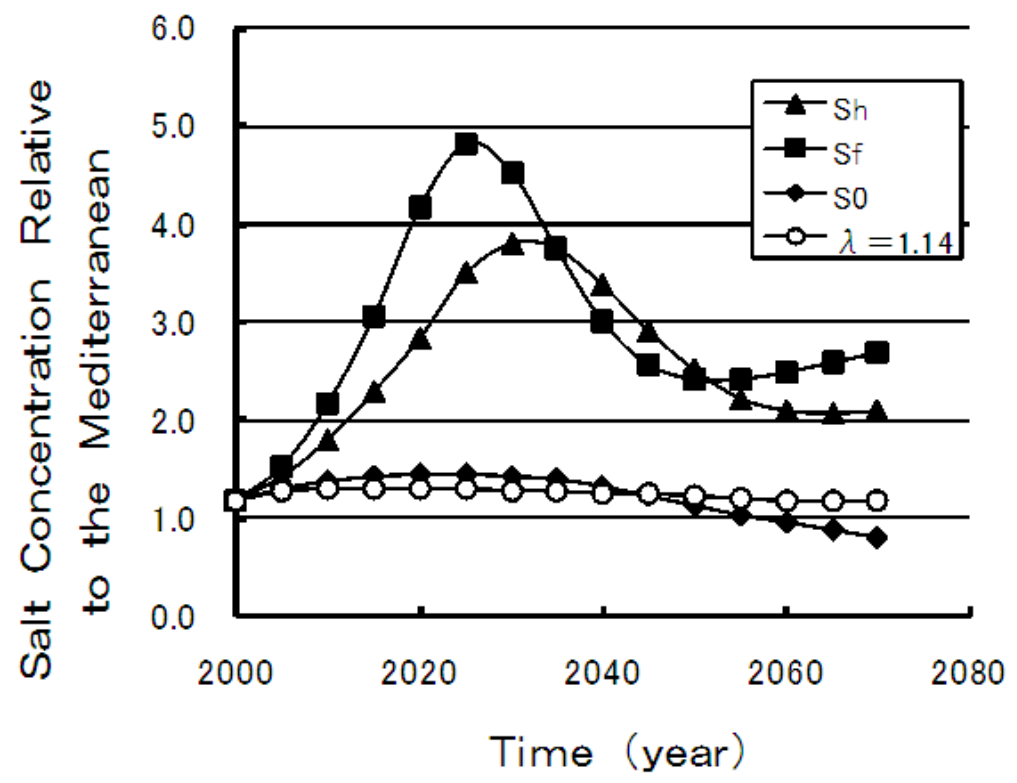

Figure 8. Projected temporal changes in the salt concentration of the Akyatan lagoon.

\section{Projected Ground Water Salinity}

Changes in ground water salinity projected under scenarios $\mathrm{S} 0$, Sh, and $\mathrm{Sf}$ in terms of the change in concentration relative to sea water between 2070 and 2000 (Figure 9) show that a high salinity zone penetrates deeper in the ground water basin beneath the lagoon compared to the current distribution of salinity (Figure 6). The vertically elongated plumes, especially for Sh and Sf, are obviously attributed to the increased salinity in the lagoon water due to the increased evaporation and decreased precipitation (Figure 8). It is of interest to note that the concentration distribution in the finger-like plumes reflects the temporal change in the salinity of the lagoon water. 


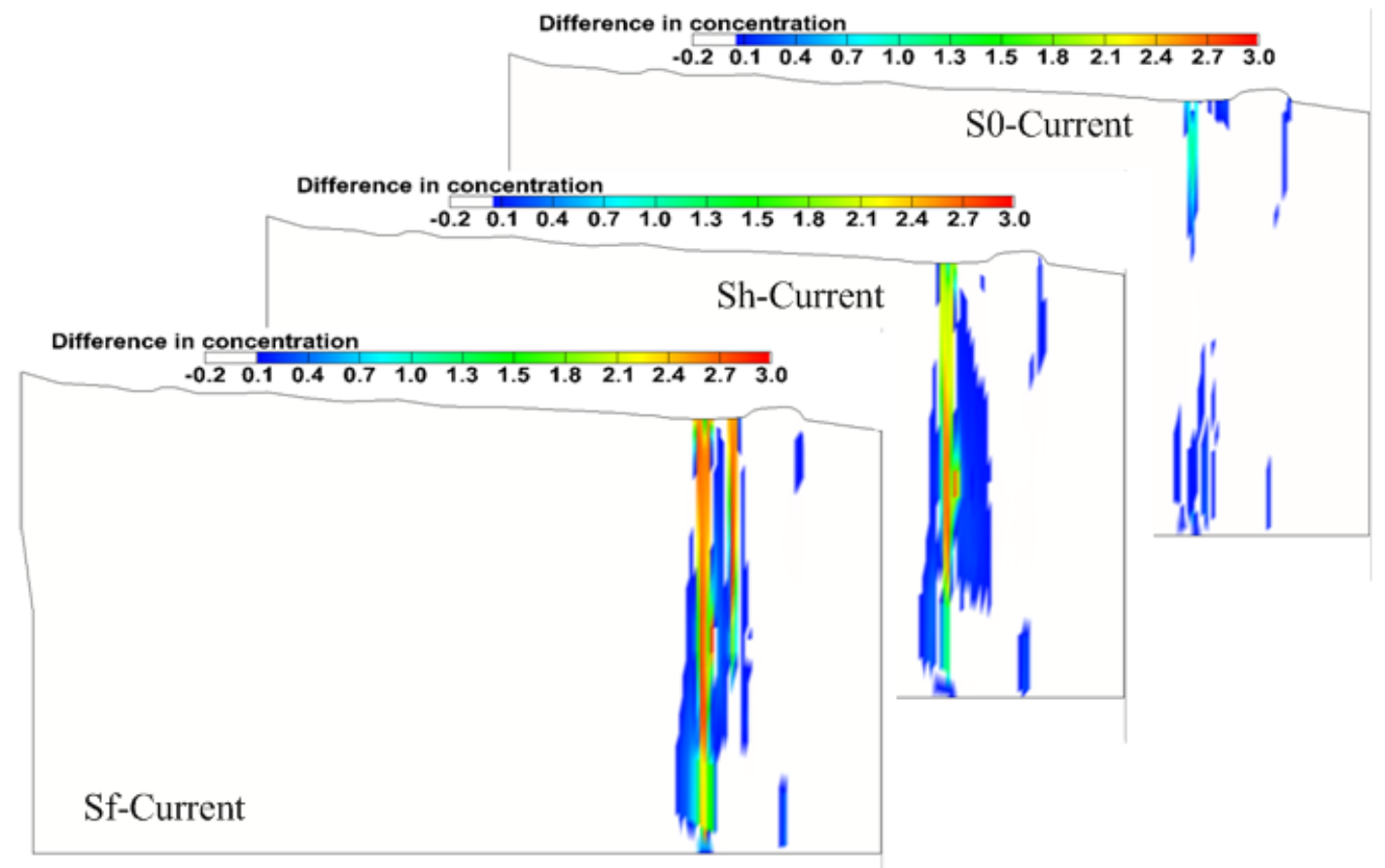

Figure 9. Difference in the relative salt concentration of ground water between the current and projected periods for scenarios S0, Sh, and Sf.

\section{Summary and Conclusions}

A new general methodology for incorporating the dynamic interaction between ground water and a saline surface water body in a numerical model was presented and applied to a field site in Turkey. The model is based on a code named SIFEC (Saltwater Intrusion by Finite Elements and Characteristics) originally developed by Fujinawa et al. (2005) that can incorporate the interaction between ground water and a saline lagoon by quantitatively evaluating the exchange of fluid and salt.

The original SIFEC is for analyzing two-dimensional, variable-density, saturated-unsaturated, coupled flow and mass-transport, and has been verified for two benchmark problems, Henry (1964) and Elder (1967). The Elder problem is specifically suited to test the linkage of density-driven ground water flow with saline surface water. The revised SIFEC code discussed in this paper can handle downward convection of salt plumes due to dense brine overlying less dense ground water. The shape and development of fingering plumes beneath a top dense brine boundary obtained by SIFEC for the Elder problem were quite similar with those simulated by Simmons et al. (1999).

SIFEC evaluates ground-water inflow and outflow at nodes along the interface with a saline surface water body and calculates the volume and mass balances of the surface water body. To illustrate the accuracy of 
the code, a series of sand box experiments were conducted, and the results simulated by SIFEC showed excellent agreement with the experimental results.

In this paper, the original SIFEC code by Fujinawa et al. (2005) was modified to account for evaporation, precipitation, runoff, overland flow, and the exchange of water and salt with the sea. The application of the revised code was used to assess impacts of sea-level rise and meteorological change on the ground water system in Lower Seyhan River Basin (LSRB) of the eastern Mediterranean coastal region of Turkey, where a long saline lagoon lies parallel with the Mediterranean Sea across a sand dune. Following calibration to current conditions, projections of changes in salinity in ground water and the lagoon were conducted using a two-dimensional cross sectional model under three scenarios consisting of sea-level rise, and changes in precipitation and evaporation. The results indicate that reduced precipitation and increased evaporation may raise the salinity in the lagoon water, which in turn induces downward convection of ground water beneath the lagoon, transporting dense brine from the lagoon into the subsurface and eventually causing drastic increases in salinity of ground water. Although the simulated case for the LSRB did not exhibit any precipitation or dissolution of salt in the lagoon, the newly proposed model also includes precipitation/dissolution processes.

Three-dimensional effects such as those created by embayments (e.g., Cherkauer and Mckereghan 1991) might change the site-specific conclusions for the LSRB. Hence, neglect of three-dimensional effects and the uncertainties associated with the hydrogeologic parameters used in the simulation could change the results. Therefore, it should be recognized that the simulated results presented in this paper show one possible outcome. However, the conceptual model and the general mathematical approach presented in the paper are demonstrated to be useful in incorporating the interaction between ground water and a lagoon in a single numerical scheme.

The basic concept for the quantitative and qualitative linkage of ground water and surface water bodies presented in this paper can be easily expanded to three-dimensional models, and can be applied to a variety of related field problems such as submerged ground water discharge (e.g., Martin et al. 2007), endangered ecosystems depending on saline ground water discharge (e.g., Harvey et al. 2007), prevention of salt water seepage to low-land areas below sea level (e.g., Masuoka et al. 2005), control of dryland salinity and water logging (e.g., Gomboso 1997), and can be applied to coastal aquifers and arid/semi-arid inland areas where estuaries, lagoons, lakes, or reservoirs are connected to ground water systems. Notably, the model can help evaluate anthropogenic impacts including climate change.

\section{Acknowledgements}


This study was conducted as a part of the research project "Impact of climate changes on agricultural production systems in arid areas" and was financially supported by the Research Institute for Humanity and Nature, Japan and Japan Society for the Promotion of Science Grant-in-Aid No.16380164. We appreciate the comments of the two anonymous reviewers and the assistance of the Editor-in-Chief, who edited the manuscript.

\section{References}

Bear, J. 1979. Hydraulics of Groundwater. New York: McGraw-Hill.

Celia, M. and E.T. Bouloutas. 1990. A general mass-conservative numerical solution for the unsaturated flow equation. Water Resources Research 26, no.7: 1483-1496.

Cetin, M. and K. Diker. 2003. Assessing drainage problem areas by GIS: A case study in the eastern Mediterranean region of Turkey. Irrig. And Drain. 52: 343-353.

Cheng, X. and M.P. Anderson. 1993. Numerical simulation of ground-water interaction with lakes allowing for fluctuating lake levels. Ground Water 31, no.6: 929-933.

Cheng, X., and M.P. Anderson. 1994. Simulating the influence of lake position on groundwater. Water Resources Research 30, no.7: 2041-2049.

Cherkauer, D.S. and P.F. McKereghan. 1991. Ground-water discharge to lakes: Focusing in embayments. Ground Water 29, no.1: 72-80.

Crowe, A.S. 1993. The application of a coupled water-balance-salinity model to evaluate the sensitivity of a lake dominated by groundwater to climatic variability. Journal of Hydrology 141: 33-73.

Elder, J.W. 1967. Transient convection in a porous medium. J.Fluid Mech. 27, no.3: 609-623.

Frind, E.O. 1982. Simulation of long-term transient density-dependent transport in groundwater. Adv. Water Resources 5: 73-88.

Fujinawa, K., K. Masuoka, T. Nagano, and T. Watanabe. 2005. Numerical simulation modeling for salt-water intrusion in predicting impacts of sea-level rise on areas below sea-level. Journal of Environmental Systems and Engineering, Japan Society of Civil Engineers VII-35, no. 790: $35-48$ (in Japanese with English abstract).

Gomboso, J., F. Ghassemi, and S.J. Appleyard. 1997. Dryland salinity in the North Stirling Land Conservation District, Western Australia: Simulation and management options. Hydrogeological Journal 5, no.1: 80-97.

Gurbuz, K. 1999. Regional implications of structural and eustatic controls in the evolution of submarine fans: an example from the Miocene Adana Basin, southern Turkey. Geol. Mag. 136, no.3: 311-319.

Harvey, F.E., J.F. Ayers, and D.C. Gosselin. 2007. Ground water dependence of endangered ecosystems: Nebraska's eastern saline 
wetlands. Ground Water 45, no.6: 736-752.

Henry, H.R. 1964. Effects of dispersion on salt encroachment in coastal aquifers. Sea water in coastal aquifers, US Geological Survey Water Supply Paper 1613-C: 70-84.

Hoaglund, J.R., G.C. Huffman, and N.G. Grannemann. 2002. Michigan basin regional ground water flow discharge to three Great Lakes. Ground Water 40, no.4: 390-406.

Iba, T., U. Kashima, T. Toyoda, K. Fujinawa, and T. Watanabe. 2008. Benchmark problems for saltwater intrusion and the influence of a lagoon on saltwater intrusion. Proc. Spring Meeting of Japanese Association of Groundwater Hydrology: 96-101 (in Japanese).

Kimura, F., A. Kitoh, A. Sumi, J. Asanuma, and A. Yatagai. 2007. Downscaling of the global warming projections to Turkey. In: $T$. Watanabe and R. Kanber (eds.) The Final Report of ICCAP. ICCAP Publication 10, Research Institute for Humanity and Nature, Japan: 21-32.

Konikow, L.F., D.J. Goode, and G.Z. Hornberger. 1996. A three-dimensional method-of-characteristics solute-transport model (MOC3D). Water-Resources Investigation Report 96-4267, U.S. Geological Survey: 87 p.

Kurttas, T. and N. Karahanoglu. 1994. Modeling of Adana Plain (Turkey) by means of finite difference method. Proc. Cukurova University $15^{\text {th }}$ Anniversary Symposium, Adana, Turkey (ISSN-10191011): 103-122.

Lee, T.M. 2000. Effects of nearshore recharge on groundwater interactions with a lake in mantled karst terrain. Water Resour. Res. 36, no.8: 2167-2182.

Martin, J.B., J.E. Cable, C. Smith, M. Roy, and J. Cherrier. 2007. Magnitudes of submarine groundwater discharge from marine and terrestrial sources: Indian River Lagoon, Florida. Water Resour. Res. 43: W05440, doi:10.1029/2006WR005266.

Masuoka, K., K. Fujinawa, K., M. Furukawa, T. Nagano, and T. Watanabe. 2005. Experimental studies for identifying the impacts of sea-level rise caused by global warming on groundwater environment in areas below sea-level. Journal of Groundwater Hydrology, Japanese Association of Groundwater Hydrology 47, no.1: 19-28 (in Japanese with English abstract).

Merritt, M.L. and L.F. Konikow. 2000. Documentation of a computer program to simulate lake-aquifer interaction using the MODFLOW ground-water flow model and the MOC3D solute-transport model. U.S. Geological Survey Water-Resources Investigations Report 00-4167: $146 \mathrm{p}$.

Nazik, A., G. Evans, and K. Gurbus. 1999. Sedimentology and paleontology with special reference to the ostracoda fauna of Akyatan Lagoon. Geosound 35: 127-147.

Sacks, L.A., J.S. Herman, L.F. Konikow, and A.L. Vela. 1992. Seasonal dynamics of groundwater-lake interactions at Donana National Park, 
Spain. Journal of Hydrology 136: 123-154.

Simmons, C.T., K.A. Narayan, and R.A. Wooding. 1999. On a test case for density-dependent groundwater flow and solute transport models: The salt lake problem. Water Resources Research 35, no.12: 3607-3620.

Simpson, M.J. and T.P. Clement. 2003. Theoretical analysis of the worthiness of Henry and Elder problems as benchmarks of density-dependent groundwater flow models. Adv Water Resour. 26: 17-31.

Solomon, S., D. Qin, M. Manning, A.B. Alley, T. Berntsen, N.L. Bindoff, Z. Chen, A. Chidthaisong, J.M. Gregory G.C. Hegerl, M. Heimann, B.Hewitson, J.B. Hoskins, F. Joos, J. Jouzel, V. Kattsov, U. Lohmann, T. Matsuno, M. Molina, N. Nicholls, J. Overpeck, G. Raga, V. Ramaswamy, J. Ren, M. Rusticucci, R. Somerville, T.F. Stocker, P. Whetton, R.A. Wood, and D. Wratt. 2007. Technical Summary. In: $S$. Solomon, D. Qin, M. Manning, Z.Chen, M. Marquis, K.B. Averyt, M. Tignor, and H.L. Miller (eds.) Climate Change 2007: The Physical Science Base. Contribution of Working Group I to the Fourth Assessment Report of the Intergovernmental Panel on Climate Change. Cambridge University Press, United Kingdom and New York, NY, USA.

van Genuchten, M.TH. 1980. A closed-form equation for predicting the hydraulic conductivity of unsaturated soils. Soil Sci. Soc. Am. J. 44: 892-898.

Vanek, V. 1993. Groundwater regime of a tidally influenced coastal pond. Journal of Hydrology 151: 317-342.

\section{Figure Captions}

Figure 1. Volume and mass balance of a lagoon connected to the sea.

Figure 2. Comparison of concentrations obtained by SIFEC (solid lines) with those of sand box experiment (closed circles): (1-e) equilibrium state of the 1st stage, (2-e and $3-i)$ equilibrium state of the 2 nd stage and initial state of the $3 \mathrm{rd}$ stage, (3-244s) after $244 \mathrm{sec}$ of the 3rd stage, (3-e) equilibrium state of the 3rd stage, and comparison of pooled-water levels by experiments and simulations (open circles at equilibrium state for (1-e) and (2-e)): (reproduced from Fujinawa et al. 2005).

Figure 3. Simulated changes in (a) the depth of lagoon water at $x=700$ $\mathrm{mm}$ during the 2 nd stage and (b) the salt concentration of lagoon water relative to salt water in the right chamber during the 3rd stage.

Figure 4. Geologic profile along a flow path and the finite element mesh.

Figure 5. Calibrated (solid line) and observed (closed circles) locations of 
the water table for the current time period. The horizontal axis is distance from the landward boundary. The heavy vertical lines indicate the location of the representative point sinks (see Figure 4).

Figure 6. Ground water velocity vectors and salt concentration relative to the Mediterranean Sea for the current time period.

Figure 7. Velocity vectors of ground water near the Akyatan lagoon.

Figure 8. Projected temporal changes in the salt concentration of the Akyatan lagoon.

Figure 9. Difference in the relative salt concentration of ground water between the current and projected periods for scenarios S0, Sh, and Sf.

\section{Appendix 1}

Galerkin Finite Element Formulation for Variable-Density Flow

A trial solution of $h_{f}$ for the two-dimensional $x^{-} z$ coordinate system is assumed to have the form:

$$
h_{f} \cong \sum_{j=1}^{m} \phi_{j}(x, z) h_{j}
$$

where $\phi_{j}$ are the linear basis functions, and $m$ is the total number of nodes in a finite element mesh. In the same way, $\rho$ is approximated by using:

$$
\rho \cong \sum_{j=1}^{m} \phi_{j}(x, z) \rho_{j}
$$

According to the Galerkin method, convolution of the residual of Equation A1 with all the basis functions over a domain $R$ leads to $\mathrm{m}$ integral equations as:

$$
\begin{aligned}
& \iint_{R} \phi_{i}\left(S S_{s}+C_{s}\right) \frac{\partial h}{\partial t} d R+\iint_{R}\left[\frac{\partial \phi_{i}}{\partial x}\left(K \frac{\partial h}{\partial x}\right)+\frac{\partial \phi_{i}}{\partial z}\left\{K\left(\frac{\partial h}{\partial z}+\frac{\rho}{\rho_{f}}\right)\right\}\right] d R \\
& -\oint_{s} \phi_{i} K\left(\nabla h+\frac{\rho}{\rho_{f}} \nabla z\right) \bullet \mathbf{n} d s=0 \quad(i=1,2, \cdots, m)
\end{aligned}
$$

where $\mathbf{n}$ is the outward normal vector. Substitution of Equations A1 and A2 into Equation A3 and application of Green's theorem to the second derivative lead to:

$$
[A]\{h\}+[B]\{\rho\}+[E]\left\{\frac{\partial h}{\partial t}\right\}=\{Q\}
$$

where 


$$
\begin{aligned}
A_{i j} & =\iint_{R} K\left(\frac{\partial \phi_{i}}{\partial x} \frac{\partial \phi_{j}}{\partial x}+\frac{\partial \phi_{i}}{\partial z} \frac{\partial \phi_{j}}{\partial z}\right) d R \\
B_{i j} & =\iint_{R} \frac{K}{\rho_{f}} \frac{\partial \phi_{i}}{\partial z} \phi_{j} d R \\
E_{i j} & =\iint_{R}\left(S S_{s}+C_{s}\right) \phi_{i} \phi_{j} d R \\
Q_{i} & =\oint_{s} \phi_{i} K\left(\nabla h+\frac{\rho}{\rho_{f}} \nabla z\right) \bullet \mathbf{n} d s
\end{aligned}
$$

Since the lumped form of the time matrix yields more reliable numerical results in solving non-linear fluid flow problems (Celia and Bouloutas $1990)$, the matrix $[E]$ is rewritten as:

$$
E^{N} i i=\sum_{j=1 R}^{n} \iint_{S}\left(S S_{s}+C_{s}\right) \phi_{i} \phi_{j} d R, \quad E^{N}{ }_{i j}=0 \quad(i \neq j)
$$

Using Equation A5 and applying the implicit difference-in-time scheme to Equation A4 leads to the matrix equation:

$$
\left([A]+\left[E^{N}\right] / \Delta t\right)\{h\}_{t+\Delta t}+[B]\{\rho\}_{t+\Delta t}=\{Q\}+\left[E^{N}\right]\{h\}_{t} / \Delta t
$$

\section{Appendix 2}

Formulation of Mass Transport using Method of Characteristics and Finite Elements

Since ground water is essentially incompressible, $c \nabla \cdot \mathbf{v}$ can be neglected with respect to $\mathbf{v} \cdot \nabla c$. Therefore, $\nabla \cdot(\mathbf{v} c)$ in Equation 5 reduces to $\mathbf{v} \cdot \nabla c$. By using the hydrodynamic derivative $d c / d t(=\partial c / \partial t+\mathbf{v} \cdot \nabla c)$, the residual $L(c)$ of Equation 5 for the $\mathrm{x}^{-} \mathrm{z}$ coordinate system is written as:

$$
L(c) \equiv \frac{d c}{d t}-\frac{\partial}{\partial x}\left(D_{x x} \frac{\partial c}{\partial x}\right)-\frac{\partial}{\partial x}\left(D_{x z} \frac{\partial c}{\partial z}\right)-\frac{\partial}{\partial z}\left(D_{z x} \frac{\partial c}{\partial x}\right)-\frac{\partial}{\partial z}\left(D_{z z} \frac{\partial c}{\partial z}\right)
$$

A trial solution for $c$ is again assumed to have the form:

$$
c \cong \sum_{j=1}^{m} \phi_{j}(x, z) c_{j}
$$

Applying the Galerkin method to the residual L(c) and using Green's theorem leads to the following $m$ integral equations:

$$
\begin{aligned}
& \iint_{R} \phi_{i} \frac{d c}{d t} d R+\iint_{R}\left[\frac{\partial \phi_{i}}{\partial x}\left(D_{x x} \frac{\partial c}{\partial x}\right)+\frac{\partial \phi_{i}}{\partial x}\left(D_{x z} \frac{\partial c}{\partial z}\right)+\frac{\partial \phi_{i}}{\partial z}\left(D_{z x} \frac{\partial c}{\partial x}\right)+\frac{\partial \phi_{i}}{\partial z}\left(D_{z z} \frac{\partial c}{\partial z}\right)\right] d R \\
& -\oint_{s} \phi_{i} D \nabla c \cdot \mathbf{n} d s=0 \quad(i=1,2, \cdots, m)
\end{aligned}
$$

Since $\nabla c \cdot \mathbf{n}=0$ applies along impermeable boundaries and outflow boundaries, Equation B3 is written in matrix form:

$$
[F]\{c\}+[G]\left\{\frac{d c}{d t}\right\}=\{0\}
$$

where 


$$
\begin{aligned}
F_{i j}= & \iint_{R}\left[D_{x x} \frac{\partial \phi_{i}}{\partial x} \frac{\partial \phi_{j}}{\partial x}+D_{x z} \frac{\partial \phi_{i}}{\partial x} \frac{\partial \phi_{j}}{\partial z}+D_{z x} \frac{\partial \phi_{i}}{\partial z} \frac{\partial \phi_{j}}{\partial x}\right. \\
& \left.+D_{z z} \frac{\partial \phi_{i}}{\partial z} \frac{\partial \phi_{j}}{\partial z}\right] d R \\
G_{i j}= & \iint_{R} \phi_{i} \phi_{j} d R
\end{aligned}
$$

By using a Taylor series, a multivariable function $c(\mathbf{x}-\mathbf{v} \Delta t)$ is expanded about a position vector $\mathbf{x}$ as:

$$
c(\mathbf{x}-\mathbf{v} \Delta t)=c(\mathbf{x})-\Delta t(\mathbf{v} \bullet \nabla) c+\frac{(\Delta t)^{2}}{2 !}(\mathbf{v} \bullet \nabla)^{2} c-\frac{(\Delta t)^{3}}{3 !}(\mathbf{v} \bullet \nabla)^{3} c+\bullet \bullet \bullet,
$$

Approximation of $c(\mathbf{x}-\mathbf{v} \Delta t)$ by the first two terms of Equation B5 leads to:

$$
v \bullet \nabla c \cong \frac{c(\mathbf{x})-c(\mathbf{x}-\mathbf{v} \Delta t)}{\Delta t}
$$

Hence, the finite difference form of the hydrodynamic derivative is given by:

$$
\frac{d c}{d t} \cong \frac{c(\mathbf{x}, t+\Delta t)-c(\mathbf{x}, t)}{\Delta t}+\frac{1}{2}\left\{\frac{c(\mathbf{x}, t)-c(\mathbf{x}-\mathbf{v} \Delta t, t)}{\Delta t}+\frac{c(\mathbf{x}, t+\Delta t)-c(\mathbf{x}-\mathbf{v} \Delta t, t+\Delta t)}{\Delta t}\right\}
$$

And the final matrix Equation takes the form:

$$
\left(\frac{[F]}{2}+\frac{[G]}{\Delta t}\right)\{c\}^{k+1}{ }_{t+\Delta t}=\left(\frac{[G]}{\Delta t}-\frac{[F]}{2}\right)\{c\}_{t}-\frac{[G]}{\Delta t}\left(\frac{\{c\}^{k}{ }_{t+\Delta t}+\{c\}_{t}}{2}-\frac{\{\bar{c}\}_{t+\Delta t}+\{\bar{c}\}_{t}}{2}\right)
$$

where $\bar{c}=c(\mathbf{x}-\mathbf{v} \Delta t)$, and $k$ is the number of iterations. Iteration continues until $\max _{1 \leq i \leq m}\left|c^{k+1}\left(\mathbf{x}_{i}\right)-c^{k}\left(\mathbf{x}_{i}\right)\right| \leq c_{c}$ is satisfied for each time step, where $c\left(\mathbf{x}_{i}\right)$ and $c_{c}$ are the concentration for node $i$ and a criterion for convergence, respectively. It should be noted that $D \nabla c \bullet \mathbf{n}=0$ applies at the outflow zones of prescribed head boundaries as well as at the impermeable boundaries.

In order to find the location $\mathbf{x}_{\mathbf{p}}$ from which a particle travels to the nodal point $\mathbf{x}_{i}$ during each time step and calculate the concentration at $\mathbf{x}_{\mathbf{p}}$, SIFEC combines an averaging scheme for nodal velocities, the first order Runge-Kutta (Euler) method for particle tracking, and a bi-quadratic interpolation for particle concentrations. Equations A6 and B8 are solved simultaneously by using a double iterative scheme, which accommodates the non-linearity arising from the unsaturated hydraulic conductivity and the coupling of the flow and solute transport equation. 